\title{
The Eight Percent Problem: Authors of Colour in the British Young Adult Market (2006-2016)
}

\author{
Melanie Ramdarshan Bold ${ }^{1}$
}

Published online: 27 July 2018

(c) The Author(s) 2018

\begin{abstract}
The conversations surrounding 'diversity' in the Anglo-American book publishing industry have increased in recent years, and often centre around the lack of representation of publishing professionals, authors, and characters of colour. This paper contextualises these discussions within British YA, a market that has grown in popularity since 2006. Through an analysis of the corpus of all Young Adult fiction titles published, in the UK, during the 2006-2016 period, this paper will investigate what percentage of the titles were created by authors of colour; to determine whether this number has risen over the years, and to pinpoint any patterns and anomalies that emerge over the time period.
\end{abstract}

Keywords Young adult fiction · YA · UKYA · Young adult publishing · Authorship · Diversity $\cdot$ Diverse YA $\cdot$ Inclusive YA $\cdot$ Authors of colour $\cdot$ British authors $\cdot$ British publishing $\cdot$ UK publishing $\cdot$ BAME authors

\section{Introduction and Background}

'Diversity' [or lack thereof] has become a buzzword in the Anglo-American book publishing industries. It is used to describe an industry that is dominated by white, middle-class, able-bodied, cisgendered, heteronormativity (in its workforce, authors, and characters) [1, 15, 19, 21, 34]. The We Need Diverse Books project defines 'diversity' as: "all diverse experiences, including (but not limited to) LGBTQIA, Native, people of color, gender diversity, people with disabilities, and ethnic,

Melanie Ramdarshan Bold m.bold@ucl.ac.uk

1 Department of Information Studies, University College London, Gower Street, London WC1E 6BT, UK 
cultural, and religious minorities" [38]. However, in the publishing industry, it is often used to describe books written by, or featuring, people of colour, and/or publishing professionals of colour. ${ }^{1}$ Two industry studies, undertaken a decade apart, found that the "old monoculture" that existed in 2004 had not improved much in the subsequent 10 years: not only were there barriers for aspiring and emerging publishing professionals but also for racialised (or 'BAME') authors [19, 21, 34]. ${ }^{2}$ Ensuing discussions have centred on cultural producers (e.g. publishing professionals) and 'representation' (e.g. the main characters in a book). This paper, however, will focus on authors of colour (AOC).

While conversations lamenting the lack of 'diversity' are mushrooming in different publishing sectors and the wider cultural industries, it is not a new discussion. In the children's and young adult (YA) sector, it is one that emerged during the Civil Rights Movement in the 1960s through a study of children's books published between 1962 and 1964: only 6.7\% of 5000 published featured African-American characters [23]. Reading 'diversely', whether that is reading about a range of cultures or books by minoritised authors, is particularly important for children and young adults because, as Larrick alerted, "There seems to be little chance of developing the humility so urgently needed for world cooperation... as long as children are brought up on gentle doses of racism through their books" [23, p. 63]. These words are as pertinent now, 50 years later, as they were then: there has been a rise in racial and religious hate crimes, and anti-immigrant sentiment, in the UK and USA, since 2016 [5, 24]. Consequently, literature that teaches empathy and understanding is crucial, especially in our formative years [30]. There have been studies since that highlight that representation of characters of colour remains low: the Cooperative Children's Book Center, University of Wisconsin-Madison, discovered that the number of representative books fell between 1985 and 1995. However, there was, if we take the same time period as this project, an increase from $7.1 \%$ ( 215 books) in 2006 to $12.9 \%$ (439 books) in 2016 [7]. In the UK, a study by CLPE found that only $1 \%$ of children's books, published in the UK in 2017, had a 'BAME' protagonist: only $4 \%$ included 'BAME' background characters [8].

In recent years, the YA community, like the wider publishing and cultural industries, appealed for more 'diversity' (in the broadest sense) in books. Although there have been many conversations, conference panels, and initiatives: YA authors of colour are still not visible in the bestseller charts, prominent books festivals, and prestigious literary prizes [29]. For example, an author of colour has never won The Carnegie Medal for Children's Literature, which was established in 1935, and the prize faced criticisms in 2017 for its all-white longlist [22]. Several grassroots projects, often led by minoritised people, such as We Need Diverse Books, have amplified the conversation in the hope of increasing representation of characters. These movements are important because there have been many cases of misrepresentation,

\footnotetext{
1 The term diversity itself is problematic because it perpetuates the notion of 'otherness', which is viewed from a dominant white lens [33].

2 The term BAME/BME (Black, Asian and Minority Ethnic) is often used in industry discussions about 'diversity'; however, this paper will use the term 'people of colour'.
} 
cultural appropriation, and stereotyping in the past. In the YA market, for example, American Heart by Laura Moriarty received numerous criticisms for its white saviour narrative and the book lost its Kirkus star as a result of an online campaign [17]. Similarly the publication of When We Was Fierce by E. E. Charlton-Trujillo and The Continent by Kiera Drake were postponed after readers complained the books perpetuated negative stereotypes [12]. One way to combat this is to encourage and support Own Voice authors. ${ }^{3}$ The idea of minoritised authors writing minoritised characters is not a new concept: Walter Dean Myers outlines how in the 1960s, "the publishing industry was talking seriously about the need for books for blacks. Publishers quickly signed up books on Africa, city living and black heroes. Most were written by white writers". The problem, according to Myers, and it is one that still exists today, is that "the industry claimed that there were simply no black authors interested in writing for children" [27].

The narrative that there are just are not enough authors of colour writing is one that is used to explain their lack of inclusion in the publishing industry; however, numerous authors of colour have countered this, saying that they have struggled to get agents or, if they do have agents, publishing deals [1, 2, 6, 29]. In particular, many authors of colour felt pressured to write identity books-i.e. books that reflected their ethnic or cultural heritage or to draw upon cultural stereotypes-in order to be, or continue being, published [20, 21, 29, 34, 37]. These books often had to cover topics such as "racism, colonialism or postcolonialism as if these were the primary concerns of all BAME people" in order to be published [21]. In addition to the pressure to be a spokesperson for their particular community, many authors of colour felt tokenised or fetishized by the publishing industry [21, 29]. Not only do many authors of colour have to ensure that their writing, according to the Jhalak prize as quoted in [6], "fulfils a romantic fetishisation of their cultural heritage" but the subsequent marketing of their books, and media coverage, can, according to Saha [32, p. 11], also "racialize" them and their books [4, 6, 18, 32, 36]. This article will not explore the author of colour-publisher relationship; however, it will note some previous studies, which discuss the implications of what Squires [37] describes as the "diversity deficit" in the publishing workforce [20, 21, 37].

Although this introduction provides only a snapshot of ethnicity in book culture, these discussions highlight the imbalance of cultural output in the Anglo-American publishing industries. This results in an inequality of production with serious cultural consequences. This paper will investigate what percentage of titles published in the time period of 2006-2016 were created by authors of colour; to determine whether this number has risen over the years, and to pinpoint any patterns and anomalies that emerge over the time period, in conjunction with discussions surrounding the lack of 'diversity' in children's and YA books. In 2016 Janet Smyth, Director of the Edinburgh Book Festival's Children's programme, described YA as, "the major publishing creation of the last decade" with sales increasing from 2006

\footnotetext{
3 The term Own Voices was originally coined by YA author Corinne Duyvis through a Twitter hashtag \#OwnVoices which encourages recommendations of books with a marginalised protagonist by YA authors who share their identity [9].
} 
[13]. As such, this time period warrants investigation. This paper is a complementary piece to a forthcoming book, which explores these issues in more depth through interviews with British YA authors of colour [29]. This paper does not purport to explain why structural inequalities exist in the publishing industry; however, it will provide data to evidence that they do exist.

\section{Methodology}

In order to better understand what books by YA authors of colour are available in the UK, a corpus of relevant titles were identified and collected on the basis of the British Library's British National Bibliography (BNB) database. The metadata team at the British Library provided a database of all books tagged with the phrase 'Young adult fiction', published between January 2006 and December 2016. This database contains 13,505 records: this was reduced to 8593 after the names of editors, illustrators, authors that were dead at the time of [first] publication (during the 2006-2016 time period), and comic book and graphic novel authors were removed.

Comics and graphic novels were not included in this list because of the multiple contributors involved in this type of publication. However, it is interesting to look at representation in comics and graphic novels. Comics and graphic novels have a history of misrepresenting 'diverse' characters and reinforcing stereotypes, although this has changed in recent years. However, they also have the potential to breakdown stereotypes and boundaries. Royal suggests that, "Because of its foundational reliance on character iconography, comics are well suited to dismantle those very assumptions that problematize ethnic representation, especially as they find form in visual language. They can do this by particularizing the general, thereby undermining any attempts at subjective erasure through universalization" [31, p. 9]. Royal argues that readers can project themselves more easily onto less detailed illustrations of characters irrespective of ethnicity, gender, etc. As such, comics and graphic novels have the potential to introduce 'diversity' to young readers in a less prescriptive, and more accessible, way. Consequently, this is a research area that warrants further study.

This research focuses on print/volume titles only: so other formats (e.g. online resources and audio books) were removed but these titles were, typically, available in print format too. The metadata did not include information such as author sex/ gender identity, ethnicity, and nationality, or the type of publisher (i.e. conglomerate, independent, or self-published). This additional information was identified through digital and printed paratextual, mostly epitextual, information (e.g. publisher and author websites, author interviews in print and online media, author information on book covers etc.). Authors were segmented by their sex/gender identity, ethnicity, ${ }^{4}$ and nationality. The data was then coded and analysed. This provided statistical

\footnotetext{
4 This was based on Office for National Statistics definitions. ONS uses the following categories to segment ethnicity: White; Mixed/multiple ethnic groups; Asian/Asian British; Black/African/Caribbean/ Black British; Other ethnic group.
} 


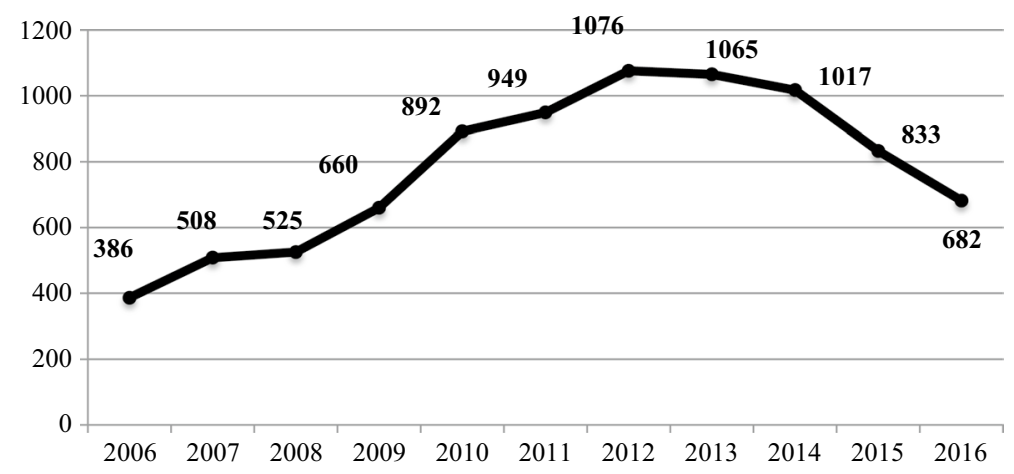

Fig. 1 Number of titles published (including different editions): 2006-2016

information about what percentage of publishing output, in this sector, could be considered as 'diverse'. In addition to the database of all titles published, an analysis of the bestselling titles of this period, based on Nielsen data was undertaken. This database included the twenty-bestselling books of 2006-2016, and the twenty-bestselling books of each year: there were 220 titles altogether. This on-going collection of titles (of all titles and bestselling titles) provides a robust overview of the key titles, trends, publishers, and authors in the British YA market.

\section{Database Analysis}

\section{Findings and Discussion}

The following is based on YA Fiction print titles written by authors who were alive at the time of first publication and in which that publication occurred in the UK between 2006 and 2016. The analysis will focus on three main areas: all of the titles published (including the various editions of a single title); unique titles published (removing all of the different editions); and individual authors (removing the different titles). ${ }^{5}$

\section{Output}

There were 8593 titles (including different/new/republished editions of titles) YA titles published between 2006 and 2016 in the UK. YA has grown in popularity in the UK with the number of titles being published each year more than doubling from 2006 to 2010. Although there were more titles being published in 2016 than 2006: the YA market peaked in 2012 (1076 titles), 2013 (1065 titles), and 2014 (1017 titles) and has been in slow decline since (see Fig. 1). This number has tailored off

\footnotetext{
${ }^{5}$ All tables and figures refer to the titles or authors published in the UK during this period.
} 


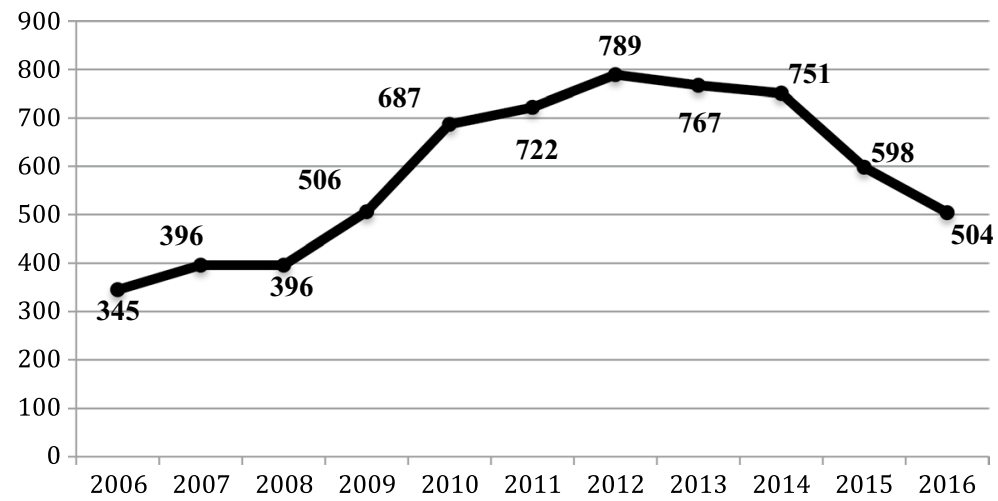

Fig. 2 Number of unique titles published, 2006-2016

since 2015 and dropped to 682 titles being published in 2016. It was during this peak period (2012-2014) that many bestselling novels ${ }^{6}$ were either first published or reissued to coincide with film adaptations or prize wins. ${ }^{7}$ Additionally, a number of other, high-profile, authors published (or republished) prolifically during this period (i.e. five books or more), showing that these years were fruitful for YA. ${ }^{8}$

There were 6461 unique titles published from 2006-2016, which is $75 \%$ of all the titles published. This means $25 \%$ of all the titles published in this period were different editions of original work. Again, 2011-2014 saw the most activity, in terms of new titles being published. Although none of the 'blockbuster' authors-e.g. Stephenie Meyer, Suzanne Collins, and John Green etc.--were particularly prolific during this period, many bestselling or midlist authors published a plethora of titles. In particular, and in reflection of all of the titles being published, sixty-four authors published five or more unique titles between 2011 and 2014. ${ }^{9}$ As we can see, from footnote 9, midlist authors, in particular, were responsible for the growth of YA output during this period. Additionally, conglomerate publishers published the majority (57\%) of the YA titles in 2006-2016: 40\% of all titles were published by independent publishers, and $2.5 \%$ were self-published.

\footnotetext{
${ }^{6}$ Such as The Hunger Games series/Suzanne Collins, The Maze Runner series/James Dashner, Fault in Our Stars/John Green, Breaking Dawn/Stephenie Meyer, I am Four/Pitticus Lore (James Frey), A Monster Calls/Patrick Ness, Divergent trilogy/Veronica Roth, and Girl Online/Zoella.

7 Many of these blockbuster authors published (or republished) prolifically in this time period: Veronica Roth (16), Suzanne Collins (15), James Dashner (14), John Green (6).

${ }^{8}$ For example: Darren Shan (24), Sophie McKenzie (18), James Patterson (18), Cassandra Clare (12), Alan Gibbons (11), Philip Pullman (11), Juno Dawson (10), David Levithan (10), Kevin Brookes (9), Scott Westerfeld (9), Melvin Burgess (8), Anne Cassidy (8), Keith Gray (8), Bali Rai (8), Sara Shepard (8), Holly Black (7), Neil Gaiman (7), Anthony Horowitz (7), Amanda Hocking (6), Keira Cass (5), Kami Garcia (5), Meg Rosoff (5), and Carlos Ruiz Zafón (5).

9 These included authors such as: Darren Shan (15), Robert Muchamore (11), David Grant (10), Sophie McKenzie (10), K. M. Peyton (10), Melvin Burgess (9), Tommy Donbavand (9), Alan Gibbons (9), Benjamin Hulme-Cross (9), Bali Rai (9), Anne Cassidy (7), Juno Dawson (7), Anthony Horowitz (6), Louise Rennison (6), Marcus Sedgwick (6), Malorie Blackman (5), Theresa Breslin (5), Cat Clarke (5), Keith Gray (5), Diana Wynne Jones (5), Zoê Marriott (5), and Cavan Scott (5).
} 


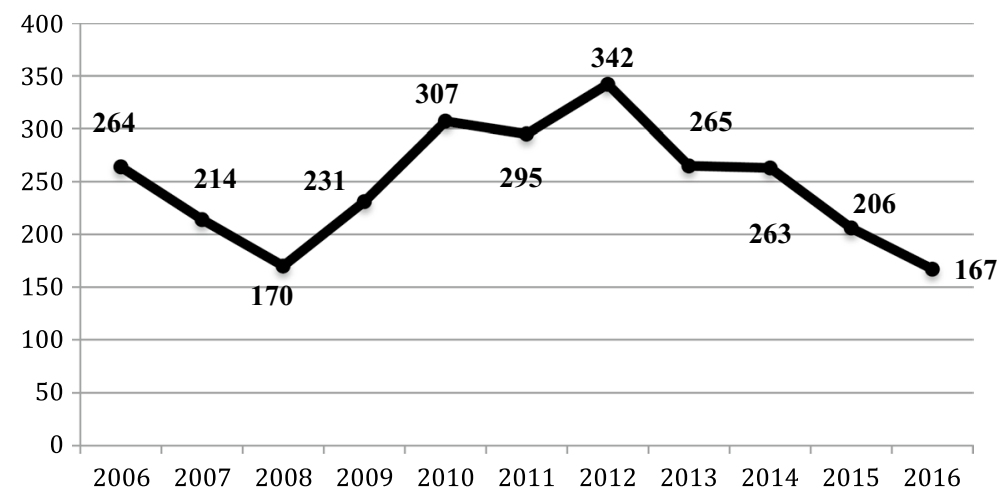

Fig. 3 Unique authors published, 2006-2016

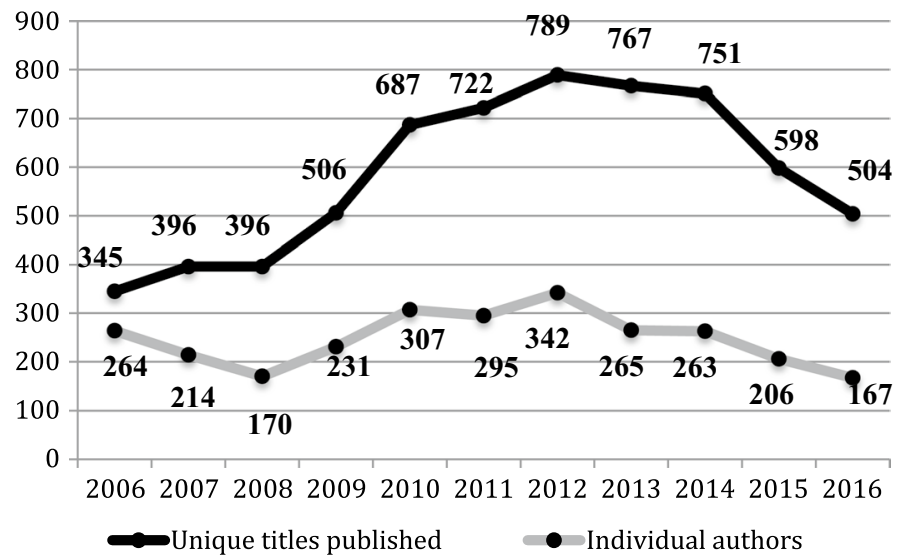

Fig. 4 Unique titles compared to individual authors, 2006-2016

\section{Individual Authors}

2724 authors published YA titles between 2006 and 2016. The 3 years between 2010 and 2012 saw the highest number of individual authors being published, with a peak of 342 different authors in 2012: this was also the year that most titles (unique and different editions) were published (Fig. 2). This number has decreased every year since 2012, dropping to 167 , the lowest number of different authors in this time period, in 2016 (Fig. 3). In fact, there were fewer different authors published in 2016 than there were in 2006: the number dropped by over a third from 264 (2006) to 167 (2016). If we look at the number of unique titles that were published in this period and compare it to the number of individual authors, we see that YA output in the UK is concentrated into the hands of fewer than 350 authors per year (Figs. 3, 4). This means that a small group of authors 


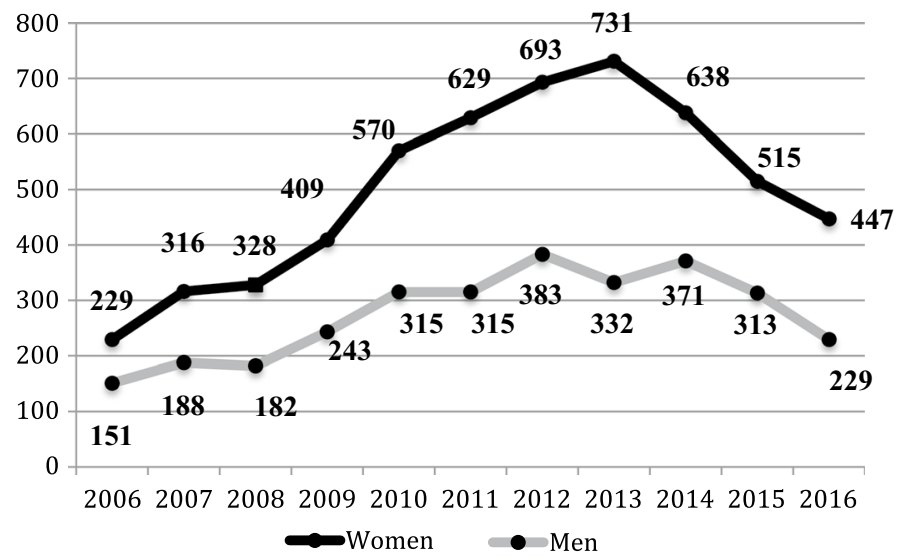

Fig. 5 No of titles per year: segmented by sex/gender identity

are producing, often prolifically, all of the YA titles published in the UK. In 2016, only 167 authors published 504 unique titles: this was an average of three titles per author.

\section{A Picture of YA Authorship}

White, cisgendered, female authors dominate YA in the UK. Although being part of this demographic does not mean that authors will write main characters of the same demographic automatically, this study found that YA, especially bestselling YA, typically feature protagonists who are white or ethnically ambiguous, cisgendered, and heterosexual. A breakdown of demographics, such as gender identity, ethnicity, nationality etc. shows how YA authorship has changed over the time period.

\section{Sex/Gender Identity}

YA has, traditionally, favoured women readers and authors such as Michael Cart, quoted in Lipsyte [26], surmises that: "In a commercially driven publishing environment, the emphasis is currently on young women" $[25,26]$. This research confirms these suspicions and demonstrates that the number of male YA authors has fallen still, since Cart made this statement. Cis and trans, but predominantly cis, women authors dominated year upon year in all of the titles published during this period. ${ }^{10}$ The 8593 (64\%) titles were predominantly written by cis and trans women ${ }^{11}$ : cis

\footnotetext{
10 At this juncture it is important to note that trans women and trans men authors were only marked as such when they self-identified. Only three authors did self-identify. Additionally one author, Juno Dawson published under her 'dead name' during this time period.

11 There is only one trans woman included in this.
} 


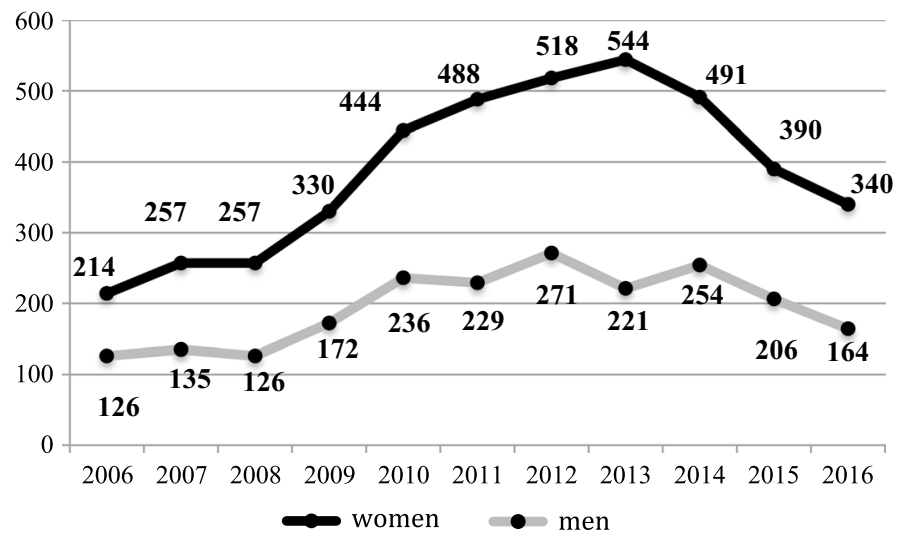

Fig. 6 Sex/gender identity of authors (individual titles)

and men wrote $35 \%$ of the titles. In fact, cis women wrote 5501 (64\%) of the titles: showing that cis women dominate the YA market. ${ }^{12}$ The highest was in 2013 when $69 \%$ of all of the titles, including different editions, were written by women in comparison to $31 \%$ written by men (Fig. 5). The share, however, does remain relatively steady, oscillating between 59\% (2006) and 69\% (2011). However, the number of titles written by men never exceeded $40 \%$. Although female authors dominated throughout this time period, male authors were better represented in 2006 (39\%) than in any other year. Things have gotten worse for male authors: in 2016 they only published around a third of all titles. When compared to the individual titles, we can see that female authors are publishing more unique titles than their male counterparts: two-thirds of all unique titles were published by cis and trans women in comparison to a third of titles published by cis and trans men (Fig. 6). Additionally, the unique authors follow the same breakdown: two-thirds (1792 authors) are women and a third are men (901 authors). Like all titles (including different editions), men fared better in 2006 (36.5\%) than in any other year. They were least well represented in the 2011-2014 time period, and in 2016 (Fig. 6). In 2013, 71\% of the unique titles published were written by women, and although this has reduced slightly since; titles by female authors still outnumber male authors, on average, around two to one. While this may come as no surprise to YA scholars and commentators, these statistics can strengthen arguments that this field of literature does not cater to male readers [26]. Lipsyte [26] argues that many of the clichés surrounding male readers-e.g. they prefer non-fiction and do not read books with female protagonists-are true. This is further compounded by a survey on Goodreads, which found readers prefer authors of their own sex: this is the reason that Joanne Rowling changed her name to the more gender neutral J. K. Rowling [10, 11]. Additionally YA can improve the reading ability of male adolescents, particularly reluctant

\footnotetext{
${ }^{12}$ Fewer than $1 \%$ of titles were written by authors without gender identity information and $0.02 \%$ were written by a male-female writing team.
} 
Table 1 Individual authors: British and American

\begin{tabular}{lclcc}
\hline Date of publication & $\begin{array}{l}\text { No. of British } \\
\text { authors }\end{array}$ & $\begin{array}{l}\text { \% of authors (that } \\
\text { year) }(\%)\end{array}$ & $\begin{array}{l}\text { No. of American } \\
\text { authors }\end{array}$ & $\begin{array}{l}\text { \% of authors } \\
\text { (that year) }(\%)\end{array}$ \\
\hline 2006 & 140 & 53.03 & 102 & 38.64 \\
2007 & 91 & 42.52 & 103 & 48.13 \\
2008 & 64 & 37.65 & 87 & 51.18 \\
2009 & 86 & 37.23 & 120 & 51.95 \\
2010 & 118 & 38.44 & 154 & 50.16 \\
2011 & 128 & 43.39 & 136 & 46.10 \\
2012 & 132 & 38.60 & 180 & 52.63 \\
2013 & 147 & 55.47 & 96 & 36.23 \\
2014 & 152 & 57.79 & 76 & 28.90 \\
2015 & 129 & 62.62 & 61 & 29.61 \\
2016 & 83 & 49.70 & 63 & 37.72 \\
Grand total & 1270 & 46.62 & 1178 & 43.25 \\
\hline
\end{tabular}

Table 2 Titles by British and American authors

\begin{tabular}{lcc}
\hline Date of publication & British authors & American authors \\
\hline 2006 & 179 & 138 \\
2007 & 204 & 163 \\
2008 & 198 & 160 \\
2009 & 245 & 235 \\
2010 & 290 & 339 \\
2011 & 325 & 339 \\
2012 & 358 & 380 \\
2013 & 395 & 307 \\
2014 & 431 & 246 \\
2015 & 358 & 199 \\
2016 & 272 & 189 \\
Total & 3255 & 1178 \\
\hline
\end{tabular}

readers [3]. Consequently, the publishing industry faces losing male readers when they are teenagers if they do not produce books with a wider appeal.

\section{Nationality}

Commentators have long speculated that English language YA "disproportionately take place in the US and UK" [16]. This research confirms this is the case in the British YA market. Anglo-American authors dominated the YA market during this time period: out of all of the individual authors $43 \%$ were American and $47 \%$ were British (Table 1). British authors dominated the YA market in 2008-2012. There was a gradual rise, from 2008, in the number of British authors being published: this 
Table $3 \%$ of titles by British author
Date of publication

$\%$ of titles by UKYA authors

(\%)

\begin{tabular}{ll}
\hline 2006 & 51.88 \\
2007 & 51.52 \\
2008 & 50.00 \\
2009 & 48.42 \\
2010 & 42.21 \\
2011 & 45.01 \\
2012 & 45.37 \\
2013 & 51.50 \\
2014 & 57.39 \\
2015 & 59.87 \\
2016 & 53.97 \\
Grand total & 50.38
\end{tabular}

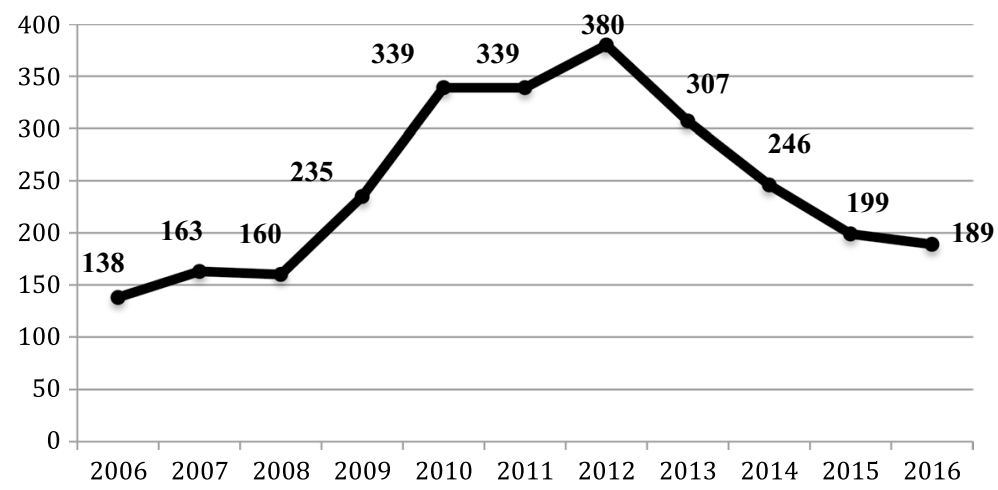

Fig. 7 Titles by American authors

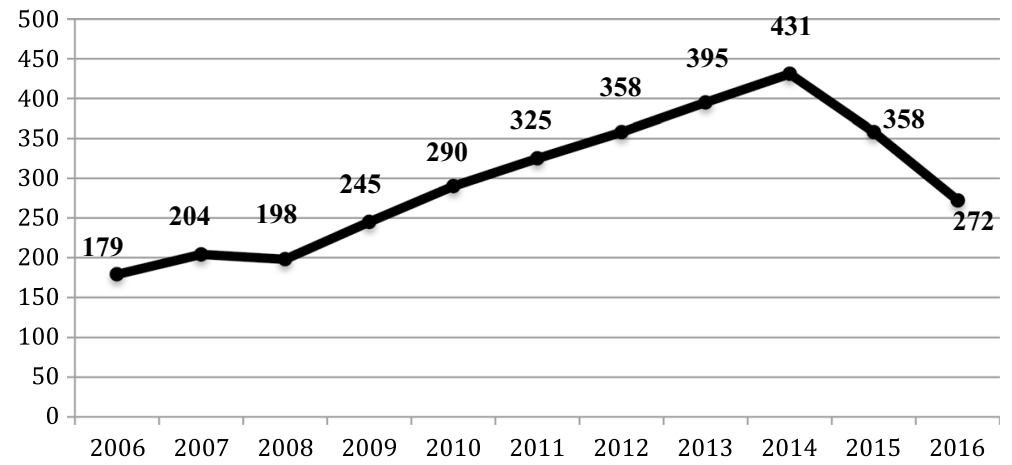

Fig. 8 Titles by British authors 


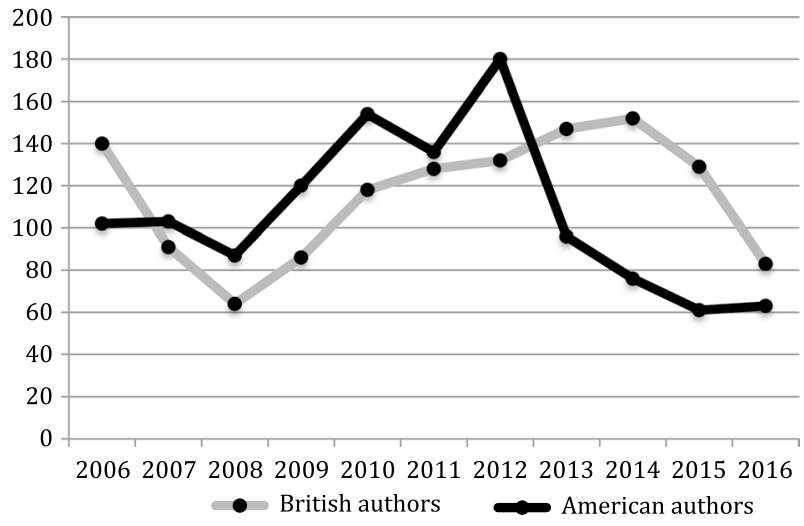

Fig. 9 American and British authors (individual authors)

Table 4 Ethnicity of author by year (individual titles)

\begin{tabular}{lclccc}
\hline Date of publication & White & $\%$ White $(\%)$ & AOC & $\%$ AOC $(\%)$ & Grand total \\
\hline 2006 & 315 & 91 & 25 & 7 & 345 \\
2007 & 346 & 87 & 44 & 11 & 396 \\
2008 & 326 & 82 & 54 & 14 & 396 \\
2009 & 438 & 87 & 61 & 12 & 506 \\
2010 & 613 & 89 & 64 & 9 & 687 \\
2011 & 653 & 90 & 55 & 8 & 722 \\
2012 & 726 & 92 & 54 & 7 & 789 \\
2013 & 700 & 91 & 47 & 6 & 767 \\
2014 & 705 & 94 & 37 & 5 & 751 \\
2015 & 556 & 93 & 34 & 6 & 598 \\
2016 & 472 & 94 & 31 & 6 & 504 \\
Grand total & 5850 & 91 & 506 & 8 & 6461 \\
\hline
\end{tabular}

peaked in 2014 with 431 titles; however, there has been a steep decline since with only 272 British authors being published in 2016 (Tables 1, 2, 3, Figs. 7, 8, 9). If we look at the titles published in 2014, the peak year, it is clear that the numbers were bolstered by several authors, who were particularly prolific in this year, publishing three or more books. ${ }^{13}$

\footnotetext{
13 2014: Ann Cassidy (3), Claire Chilton (3), Juno Dawson (3), Echo Freer (3), Alan Gibbons (3), Andrew Goodman (3), Michelle Harrison (3), Simon J. Morley (3), Robert Muchamore (3), Townsend, John (3), Mark Wright (3), Tim Collins (4), Andy Lane (4), Tony Lee (4), K. M. Peyton (4), Joanna Nadin (4), Linda Newbery (4), Cathy Hopkins (4), Bali Rai (4), Cavan Scott (5), Darren Shan (6), Dee Phillips (6) Benjamin Hulme-Cross (6), Tommy Donbavand (9), Helen Orme (14).
} 


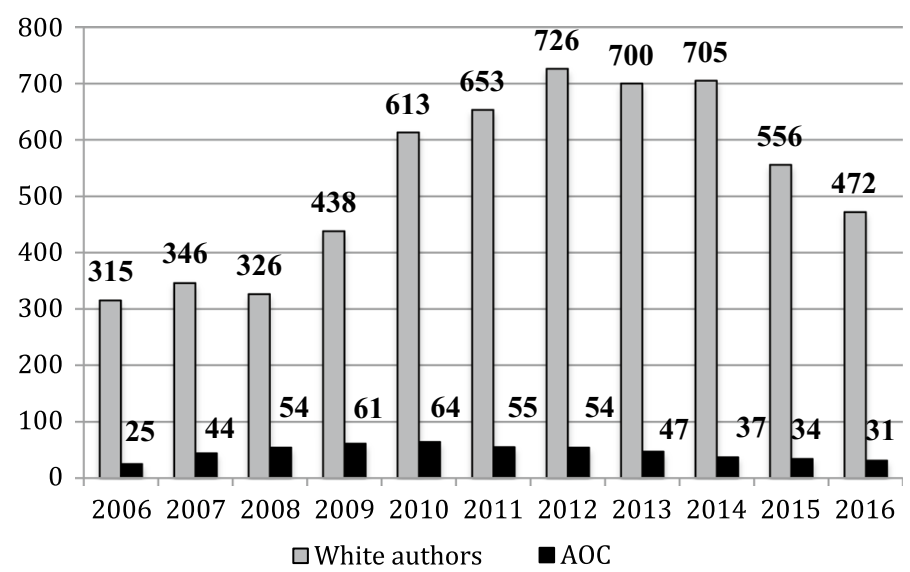

Fig. 10 Unique titles by author ethnicity

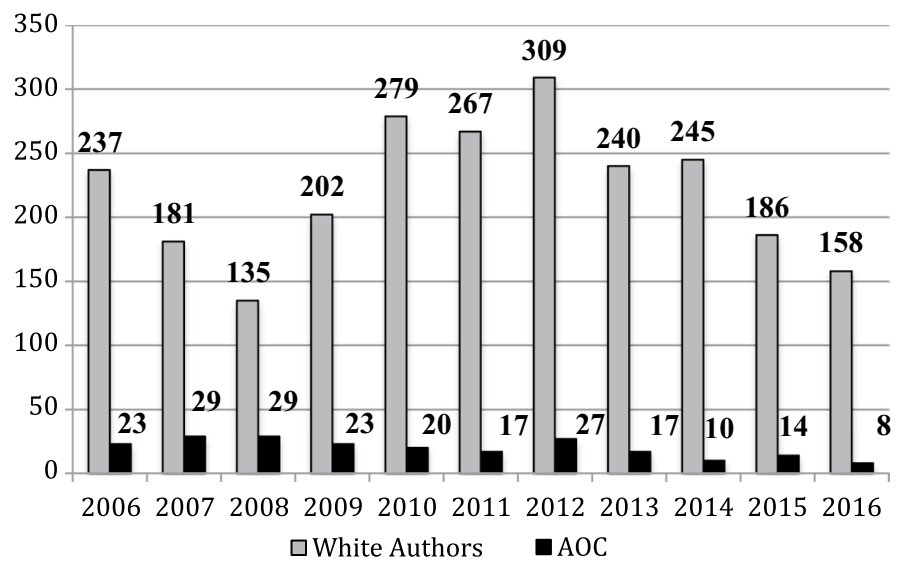

Fig. 11 Individual authors by ethnicity

\section{Ethnicity}

Authors of colour were not well represented in the British YA market between 2006 and 2016. If we look at the ethnicities of the authors publishing unique titles, we can see that the number of titles written by authors of colour has remained fairly static (i.e. always between 25 and 64 titles per year) from 2006 to 2016. There have also never been more than 100 titles published by authors of colour in any given year (the highest was 64 titles in 2010). Overall, authors of colour wrote $8 \%$ of the unique titles (506 titles). Additionally, if we look at Table 4, we can see that even though slightly more titles by authors of colour were published in 2016 (31) to 2006 (25) when we look at how many were published in comparison to the number each year, authors of colour were less well represented: $7 \%$ of all individual titles published in 


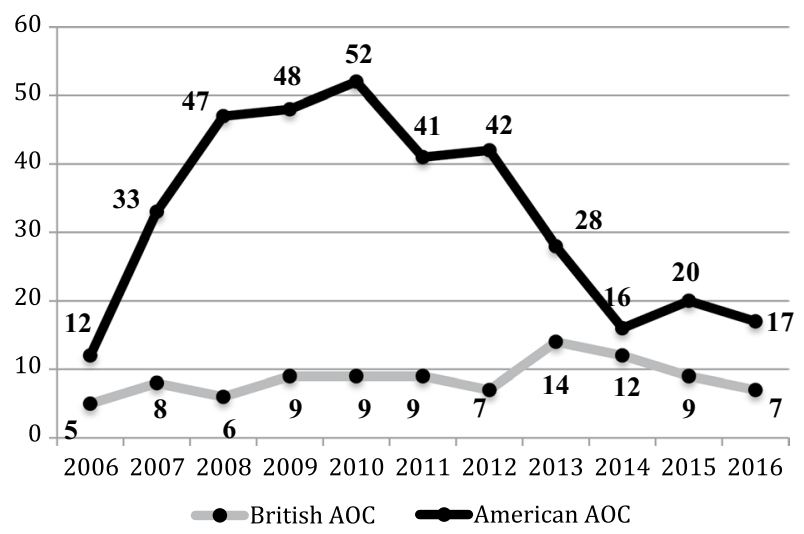

Fig. 12 Titles by authors of colour, by nationality

2006 were by authors of colour, this dropped to $6 \%$ in 2016 . The 3 -year period from 2007 to 2009 was the most representative: in 2008, authors of colour wrote $14 \%$ of the titles (around the same percentage of ethnic minorities in the UK population). Surprisingly, the number of titles written by authors of colour dropped from 2010 onwards, reaching a low in 2014 (5\% of titles written by authors of colour), despite 2010-2014 being the most productive time period for YA publishing. Although publishers produced more titles during this period they were predominantly written by white authors (Figs. 10, 11).

If we look at the individual authors being published between 2006 and 2016, it is clear that white, cis women authors dominate: 58\% (1594 authors) of all of the authors. Overall, $8 \%$ (217 authors) of all of the YA authors were authors of colour and $90 \%$ (2439 authors) were white. ${ }^{14}$ This study found that the representation of authors of colour has decreased since it peaked in 2007-2008, despite conversations about 'diversity' in the publishing industry, and the subsequent rise in 'diversity' initiatives [1, 2, 19, 28, 35, 37]. Fewer authors of colour were published in 2016 than 2006: nearly half as many were published in 2016 (4.79\% of all authors) than in 2006 (8.7\% of all authors). Authors of colour were best represented in 2008 when they accounted for $17 \%$ of all authors, as outlined above, there has been a decline ever since.

White female authors were in the majority (59\%: 1595 authors) followed by white male authors (31\%: 841 authors). Although only 6\% (170) of the YA authors were women of colour, men of colour fared the worst: only $1.7 \%$ (46) of all of the YA authors were men of colour. Male authors of colour also accounted for only $1.4 \%$ of the unique titles. Female authors were more likely to be of colour than male authors: $9.5 \%$ of the female authors were of colour in comparison to $5 \%$ of male authors. Additionally authors of colour were less likely to be male than their white counterparts: $78 \%$ of authors of colour were female in comparison to $65 \%$ of white

$\overline{14}$ It was not possible to get information for the remaining $2.5 \%$ of authors. 
Table 5 Unique British authors by ethnicity

\begin{tabular}{|c|c|c|c|c|}
\hline AOC/white & $\begin{array}{l}\text { Date of } \\
\text { publica- } \\
\text { tion }\end{array}$ & $\begin{array}{l}\text { Count of authors } \\
\text { by year/ethnicity }\end{array}$ & $\%$ & $\begin{array}{l}\text { No. of British } \\
\text { authors (total) }\end{array}$ \\
\hline \multirow[t]{11}{*}{ White authors } & 2006 & 136 & 97 & 140 \\
\hline & 2007 & 87 & 96 & 91 \\
\hline & 2008 & 62 & 97 & 64 \\
\hline & 2009 & 80 & 93 & 86 \\
\hline & 2010 & 110 & 93 & 118 \\
\hline & 2011 & 118 & 92 & 128 \\
\hline & 2012 & 124 & 94 & 132 \\
\hline & 2013 & 134 & 91 & 147 \\
\hline & 2014 & 144 & 95 & 152 \\
\hline & 2015 & 120 & 93 & 129 \\
\hline & 2016 & 81 & 98 & 83 \\
\hline Total & & 1196 & & \\
\hline \multirow[t]{11}{*}{$\mathrm{AOC}$} & 2006 & 4 & 3 & 140 \\
\hline & 2007 & 2 & 4 & 91 \\
\hline & 2008 & 2 & 3 & 64 \\
\hline & 2009 & 5 & 6 & 86 \\
\hline & 2010 & 3 & 2.5 & 118 \\
\hline & 2011 & 4 & 3 & 128 \\
\hline & 2012 & 5 & 4 & 132 \\
\hline & 2013 & 7 & 4 & 147 \\
\hline & 2014 & 2 & 1 & 152 \\
\hline & 2015 & 5 & 4 & 129 \\
\hline & 2016 & 1 & 1 & 140 \\
\hline Total & & 40 & & \\
\hline Grand total & & 1236 & & 1270 \\
\hline
\end{tabular}

authors, and only $21 \%$ of authors of colour were male in comparison to $35 \%$ of their white counterparts. It is clear from these statistics that there is a scarcity of male YA authors of colour: something that is also mirrored in the adult fiction market [2]. The most published group were white, American, female authors: $42 \%$ of all authors were from this group. ${ }^{15}$ Additionally, American authors were also more likely to be of colour: $11 \%$ of the American authors were of colour in comparison to $3 \%$ of the British authors. This could be because they have already proved the surety of their sales in the American market. American authors of colour were better represented than their British counterparts: $132(61 \%)$ of the authors of colour were American, while only $40(18.5 \%)$ were British (Fig. 12). This means only $1.5 \%$ of all the

\footnotetext{
15 It can be noted that many of the authors were attractive (and thus highly marketable, in the researcher's opinion), young, white women. This cannot, of course, be quantified because physical attractiveness is subjective and many author profiles did not include the author's age.
} 


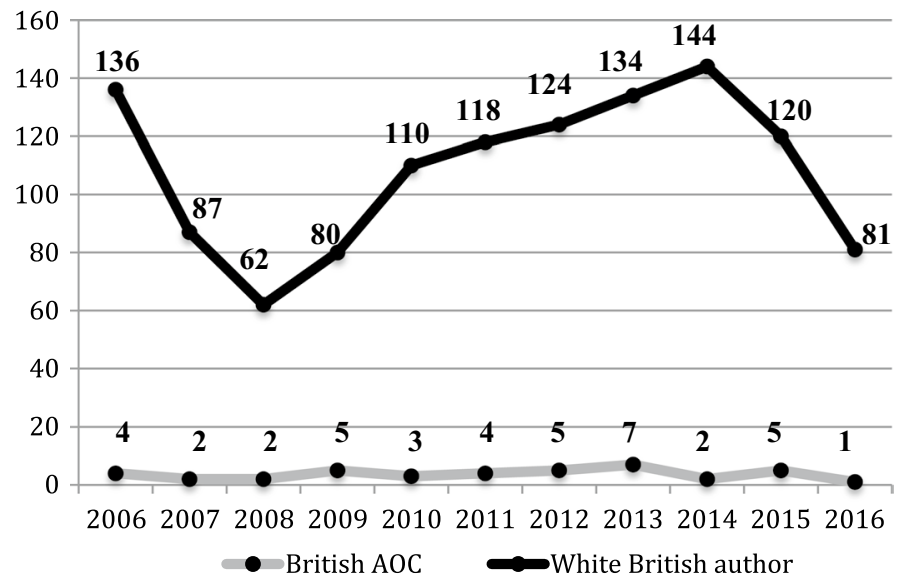

Fig. 13 Unique British authors by ethnicity

YA authors published in the British publishing industry, between 2006 and 2016, were British authors of colour. If we look at gender identity: only $0.4 \%$ of all of the authors were British men of colour and $1 \%$ were British women of colour. Furthermore, as we can see in Table 5, British authors of colour were less well represented, amongst British authors, in 2016 than they were in 2006 (Fig. 13).

There were ninety-five titles, written by forty British authors of colour, published between 2006 and 2016: 1.5\% of all unique titles published during this period. 2013 and 2014 saw the highest number of titles by British authors of colour. If we look at each year, this might be because, in 2013, both Malorie Blackman and Bali Raithe heavyweight British YA authors of colour-both published three titles each (Rai published two editions of Trouble: two tales from Devana High in addition to Shivers, while Blackman published three individual titles: John for Short; Noble Conflict; and Trust me). While Catherine Johnson, another seasoned British YA author of colour, published two individual titles: Cuts Deep and Saw Bones. In 2014, Rai published four individual titles: Old dog, new tricks; Dream on; Kiss of death; and Web of darkness. Blackman also published a new edition of Noble Conflict in 2014: The reason for the peak is again the productive nature of two key authors: Bali Rai and Malorie Blackman, who published seven (all editions) and four titles, respectively, in these 2 years. This means the 'burden of responsibility'-a concept that is explored further in the partner book-falls upon the shoulders of two experienced authors. When looking at what backgrounds the forty British authors were from, it was, predominantly, either Black British (17 authors: 42.5\%) or Asian British, from Indian subcontinent (12 authors: 35\%). Although a fifth of the authors had mixed heritages (8 authors: $20 \%$ ).

Authors of colour were more likely to publish with conglomerates, and less likely to self-publish and publish with independent publishers, than their white counterparts: $58 \%$ of titles written by authors of colour were published by conglomerates in comparison to $53 \%$ of white authors; $41 \%$ of titles by authors of colour were published by independents in comparison to $43 \%$ of white authors; and $1 \%$ of titles, 
written by authors of colour, were self-published in comparison to $6 \%$ of white authors. However, it is important to note that this figure is skewed by the import of American authors. White American authors were more likely to be published by conglomerate publishers than any other demographic: $66 \%$ of white American authors were published by conglomerates in comparison to $64 \%$ of American authors of colour, $37.5 \%$ of British authors of colour, and $34 \%$ of White British authors. This is likely to be because American authors have already demonstrated the surety of their sales in the American market before being published in the UK. On the other hand British authors of colour were more likely to be published by independent companies (57.5\% of British authors of colour) than their white British counterparts (55\% of white British authors). During the 2006-2016 time period, authors of colour were likely to publisher fewer titles than white authors: the average number of titles (including second editions) written by authors of colour was 2.8 published per author in comparison to white authors who published on average 3.23 titles per author.

\section{Bestsellers List Analysis (2006-2016)}

When compared to the twenty bestselling YA titles in 2006-2016, based on Nielsen sales data, authors of colour were not as well represented in bestselling titles (including duplicates) than in all YA output during this period (Table 6). Only one (5\%) of the top 20 bestselling YA titles in the UK between 2006 and 2016 was by an authors of colour: Noughts and Crosses by Malorie Blackman, which was the 19th most popular book. This is lower than the number of all YA titles published in the UK where $7 \%$ were by authors of colour. However, authors of colour were better represented in terms of the individual authors being published. The top twenty titles were written by seven authors-five women and two men-however, two authors dominated the list (70\% of all titles): Stephenie Meyer had eight titles on the list—all different editions and various spin offs of her Twilight series-while Suzanne Collins had six titles, all different editions of her Hunger Games series. As noted above, Malorie Blackman was the only author of colour on the list, which meant that $14 \%$ of all of the top twenty bestselling authors were of colour. This is significantly more than the overall individual authors published during this period: $8 \%$ of all unique authors were of colour. American authors dominate the bestseller list (taking all of the top ten spots) moreso than the overall output: four American authors (57\%) and three British and Irish authors (43\%). All titles were published by some of the biggest publishers in the UK: the Big Five published nineteen of the titles.

Neither white nor authors of colour are obliged, or limited, to write protagonists that reflect their ethnic or cultural heritage; however the bestselling books did reflect the white, able-bodied, heteronormativity of the authors. Ninety percent (18) of the bestselling YA titles of 2006-2016 feature white, heterosexual, able-bodied, cisgender main protagonists (human or otherwise). Only Noughts and Crosses: Book 1 (the 19th most popular book) and The Eldest Book Two: The Inheritance Cycle (the twentieth most popular book) featured people of colour as the main protagonists. 


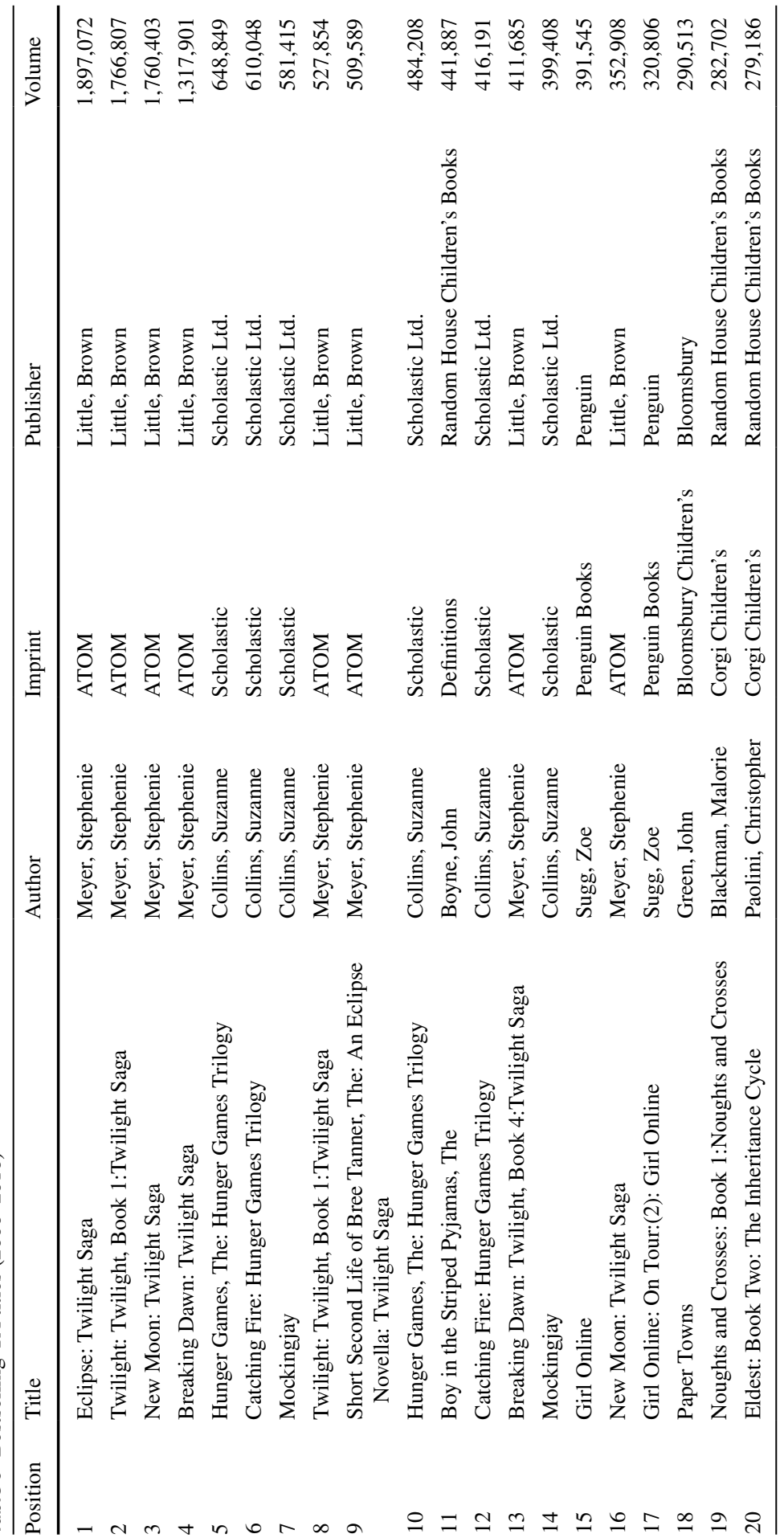


Table 7 Bestselling titles, year by year: AOC representation

\author{
2006: Malorie Blackman (no. 15, 16) \\ 2007: Malorie Blackman (no. 17) \\ 2008: None \\ 2009: Kristin Cast [with her mum PC Cast] (no. 9, 10, 12, 14, 15) \\ 2010: Kristin Cast [with her mum PC Cast] (no. 18) \\ 2011: Kristin Cast [with her mum PC Cast] (no. 9) \\ 2012: None \\ 2013: Kami Garcia (no. 2) \\ 2014: None \\ 2015: None \\ 2016: Nicola Yoon (no. 8)
}

If we look at the twenty-bestselling titles year by year (i.e. a collation of the twenty bestselling books of each year, 2006-2016) there were 59 authors/author partnerships, 62 individual authors, and 220 titles (including new editions). Men were better represented in the bestseller list than they were in the overall output: there were 36 female authors (57\% of all the bestselling authors) and 26 male authors (42\% off all the bestselling authors). Like the overall list, Anglo-American authors dominate the bestseller list: 29 British authors (47\%) and 28 American authors (45\%). As we can see from Table 7, there were four authors of colour writing twelve titles: this equated to $6.5 \%$ of the authors and $5 \%$ of the titles. A mother-daughter writing team-P. C. \& Kristin Cast-wrote seven of these titles. ${ }^{16}$ All four of the bestselling authors of colour are women. Only one of the authors of colour (Malorie Blackman) was British-1.6\% of all bestselling authors-publishing three titles/two unique titles: $1.4 \%$ of all bestselling titles and unique bestselling titles. There were 143 unique titles in the bestseller lists: authors of colour wrote $8 \%$ of these (11 titles); female authors, or female-female writing teams, wrote $61 \%$ (87 titles); and male authors, or male-male writing teams, wrote $38.5 \%$ of the titles (55). This shows that the number of bestselling titles are slightly more representative than the overall lists-in terms of inclusion of authors of colour and male authorsultimately, titles by female authors have more subsequent editions and reprints, and are thus more popular overall. Overall, the percentage of titles by authors of colour (including reprint/new editions) and the representation of individual authors of colour was lower on the bestseller lists (year by year) than all of the titles and individual authors published in this time period. This demonstrates that mainstream YA readers focus on the works of (less than) a handful (4) of authors of colour. In fact, there were more bestselling titles by authors called John (14), during this period, than bestselling authors of colour (11). ${ }^{17}$ This last point related to a 2016 study of the UK's 100 bestselling books in 2016 (in the UK) where British authors of colour wrote $1.7 \%$ of the titles: there were more authors named David on the bestseller list

\footnotetext{
16 PC Cast is a white, female writer.

17 At this juncture, it is important to note that John Green wrote most of these titles.
} 
than authors of colour [14]. If we take this figure into account, YA authors of colour were less likely to be on the bestseller list than authors of colour that wrote literary fiction. This aligns with a 2015 survey, which had more literary fiction author respondents than the more mass-market genres [21].

\section{Conclusion}

As noted in the introduction, the main purpose of this paper is to provide statistical evidence to support arguments about the lack of authors of colour being published in the UK publishing industry. YA, in the UK, has flourished since 2006; however, in recent years the sector has contracted after a particularly vibrant period in 2010-2014. This period also saw bestselling books - such as the Twilight and Hunger Games series-being adapted into blockbuster films: indicating the lucrative, mass-market appeal of this field of literature. Although there were more unique titles published in 2016 than in 2006, this study found that those titles were written by a smaller selection of authors: the majority of whom came from one particular demographic. This research found that white, Anglo-American female authors dominated this field of literature but female and male authors (particularly British) of colour did not fare so well over the years. Male authors of colour were particularly poorly represented, and account for both a very small percentage of the titles published and the number of authors being published. There are many reasons that contribute to this dearth of authors of colour-for example, structural inequalities, unconscious biases in the publishing industry, the struggle to earn a living as an author, and (ironically) the lack of author role models etc.- - which will be explored further in the complementary book [29]. This article will not offer any practical solutions to this problem it simply provides evidence that the publishing industry is, at least in part, responsible. It is important to note that the situation is, despite the spate of diversity initiatives (aimed at authors and publishing professionals), worsened for YA authors of colour: they accounted for fewer titles in 2016 than they did in 2006. Consequently, the publishing industry needs to engage in more sustainable action, rather than discussions, to help shift the entire publishing culture, which is clearly outdated for, and not reflective of, the communities it serves. Until this happens, these dire statistics will not change significantly.

Open Access This article is distributed under the terms of the Creative Commons Attribution 4.0 International License (http://creativecommons.org/licenses/by/4.0/), which permits unrestricted use, distribution, and reproduction in any medium, provided you give appropriate credit to the original author(s) and the source, provide a link to the Creative Commons license, and indicate if changes were made.

\section{References}

1. Akbar A. Diversity in publishing-still hideously middle-class and white? The Guardian. 2016. https://www.theguardian.com/books/2017/dec/09/diversity-publishing-new-faces. Accessed 4 July 2018. 
2. Akbar A. Could there really be only one new black male novelist in Britain?. The Guardian. 2017. https://www.theguardian.com/commentisfree/2016/nov/17/one-new-black-male-novelist-britainpublishing. Accessed 4 July 2018.

3. Ballash KM. Remedial high school readers can recover, too! J Read. 1994;3.1(8):686-7.

4. Brouillette S. Postcolonial writers in the global literary marketplace. Basingtoke: Palgrave Macmillan; 2007.

5. Bulman M. Brexit vote sees highest spike in religious and racial hate crimes ever recorded. Independent. 2017. https://www.independent.co.uk/news/uk/home-news/racist-hate-crimes-surge-torecord-high-after-brexit-vote-new-figures-reveal-a7829551.html. Accessed 4 July 2018.

6. Cain S. Chair of BAME prize slams UK publishers after lack of submission. The Guardian. 2016. https://www.theguardian.com/books/2016/nov/19/bame-prize-slams-uk-publishers-sunny-singh -jhalak-diversity-britain. Accessed 4 July 2018.

7. CCBC. Publishing statistics on children's books about people of color and first/native nations and by people of color and first/native nations authors and illustrators. CCBC. http://ccbc.education.wisc. edu/books/pcstats.asp. Accessed 4 July 2018.

8. CLPE. Reflecting realities—a survey of ethnic representation within UK children's literature 2017. CLPE. https://clpe.org.uk/library-and-resources/research/reflecting-realities-survey-ethnic-repre sentation-within-uk-children. Accessed 17 July 2018.

9. Duyvis C. '\#ownvoices', Corinne Duyvis. http://www.corinneduyvis.net/ownvoices/ (2018). Accessed 23 March 2018.

10. Elizabeth D. J.K. Rowling explains the reason behind her pen name. Teen Vogue. 2017. https:// www.teenvogue.com/story/jk-rowling-reason-pen-name. Accessed 4 July 2018.

11. Flood A. Readers prefer authors of their own sex, survey finds. The Guardian. 2014. https://www. theguardian.com/books/2014/nov/25/readers-prefer-authors-own-sex-goodreads-survey. Accessed 4 July 2018.

12. Flood A. Publisher delays YA novel amid row over invented black "street dialect". The Guardian. 2016. https://www.theguardian.com/books/2016/aug/16/delays-ya-row-over-invented-black-verna cular-when-we-was-fierce. Accessed 4 July 2018.

13. Flood A. Edinburgh international book festival reveals "bold, creative" lineup. The Guardian. 2016. https://www.theguardian.com/books/2016/jun/09/edinburgh-international-international-book-festi val-reveals-lineup-gordon-brown-judith-kerr-jonathan-safran-foer. Accessed 4 July 2018.

14. Flood A. Authors called David more likely to be on bestseller lists than BAME writers. The Guardian. 2016. https://www.theguardian.com/books/2016/nov/08/authors-called-david-more-likely-tobe-on-bestseller-lists-than-bame-writers. Accessed 4 July 2018.

15. Flood A. UK publishing industry remains $90 \%$ white, survey finds. The Guardian. 2017. https:// www.theguardian.com/books/2017/sep/06/uk-publishing-industry-remains-90-white-survey-finds. Accessed 4 July 2018.

16. Hansen J. Seven YA novels that show the lives of teens across the world. The Guardian. 2015. https ://www.theguardian.com/childrens-books-site/2015/sep/16/seven-ya-novels-that-show-the-lives-ofteens-across-the-world. Accessed 4 July 2018.

17. Heller N. Kirkus reviews and the plight of the "problematic" book review. New Yorker. 2017. https ://www.newyorker.com/culture/cultural-comment/kirkus-reviews-plight-of-the-problematic-bookreview. Accessed 4 July 2018.

18. Huggan G. The postcolonial exotic: marketing the margins. London: Routledge; 2001.

19. Inclusive Minds. Developing a charter for inclusion and diversity. Inclusive Minds. 2015. http:// www.inclusiveminds.com/blog.php. Accessed 4 July 2018.

20. Kean D. In full colour: cultural diversity in publishing today. London: Bookseller Publications; 2004.

21. Kean D. Writing the future Black and Asian authors and publishers in the UK marketplace. Spread the Word. 2015. https://www.spreadtheword.org.uk/writing-the-future. Accessed 4 July 2018.

22. Kean D. All-white Carnegie medal longlist provokes anger from children's authors. The Guardian. 2017. https://www.theguardian.com/books/2017/feb/16/all-white-carnegie-medal-longlist-anger -childrens-authors-philip-pullman. Accessed 4 July 2018.

23. Larrick N. The all-white world of children's books. Saturday Rev Lit. 1965;48(11):63-5.

24. Levin B, et al. New data shows US hate crimes continued to rise in 2017. The Conversation. 2017. https://theconversation.com/new-data-shows-us-hate-crimes-continued-to-rise-in-2017-97989. Accessed 4 July 2018. 
25. Lewit M. Why do female authors dominate young-adult fiction? The Atlantic. 2012. https://www. theatlantic.com/entertainment/archive/2012/08/why-do-female-authors-dominate-young-adult-ficti on/260829/. Accessed 4 July 2018.

26. Lipsyte R. Boys and reading: is there any hope? New York Times. 2011. https://www.nytim es.com/2011/08/21/books/review/boys-and-reading-is-there-any-hope.html. Accessed 4 July 2018.

27. Myers WD. Children's books; 'I actually thought we would revolutionize the industry. New York Times. 1986. https://www.nytimes.com/1986/11/09/books/children-s-books-i-actually-thought-wewould-revolutionize-the-industry.html?pagewanted=all. Accessed 4 July 2018.

28. Onwuemzi NJ. Publishers must go further to reach diverse groups. The Bookseller. 2015. https ://www.thebookseller.com/news/marlon-james-life-after-winning-man-booker-prize-317875. Accessed 4 July 2018.

29. Ramdarshan Bold M. Inclusive young adult fiction: authors of colour in the United Kingdom, 20062016. 2018 (Forthcoming).

30. Rasinski TV, Padak N. Multicultural learning through children's literature. Lang Arts. 1990;67(6):576-80.

31. Royal DP. Introduction: coloring America: multi-ethnic engagements with graphic narrative. MELUS. 2007;32(3):7-22.

32. Saha A. The rationalizing/racializing logic of capital in cultural production. Media Ind. 2016;3(1):1-16.

33. Saha A. Race and the cultural industries. London: Polity; 2018.

34. Shaffi S. Diversity report finds mono-culture prevails in publishing. The Bookseller. 2015. http:// www.thebookseller.com/news/diversity-report-finds-mono-culture-prevails-publishing. Accessed 4 July 2018.

35. Shukla N, et al. How do we stop UK publishing being so posh and white? Guardian. 2015. https ://www.theguardian.com/books/2015/dec/11/how-do-we-stop-uk-publishing-being-so-posh-white -male. Accessed 4 July 2018.

36. Squires C. Too much Rushdie, not enough romance? The UK publishing industry and BME (black minority ethnic) readership. In: Benwell B, Procter J, Robinson G, editors. Postcolonial audiences: readers, viewers and reception. Abingdon: Routledge; 2012. p. 99-111.

37. Squires C. Publishing's diversity deficit. Cameo Cuts: University of Leicester; 2017. https://www2. le.ac.uk/institutes/cameo/cameo-cuts-1/cuts-2. Accessed 4 July 2018.

38. We Need Diverse Books. About WNDB, We Need Diverse Books. 2016. https://diversebooks.org/ about-wndb. Accessed 4 July 2018. 